\title{
Sleep Before and After Retirement
}

\author{
Saana Myllyntausta ${ }^{1} \cdot$ Sari Stenholm ${ }^{1}$
}

Published online: 24 October 2018

(C) The Author(s) 2018

\begin{abstract}
Purpose of Review In this review, we focus on the association of sleep and retirement from two perspectives. Firstly, we examine the role of sleep during the working years on retirement timing. Secondly, we examine how sleep changes during the transition to retirement.

Recent Findings Persons with sleep difficulties are more likely to retire due to health problems, such as depression and musculoskeletal disorders. Retirement, on the other hand, is associated with both increased sleep duration and decreased sleep difficulties, mainly premature awakenings and nonrestorative sleep.

Summary Promotion of sleep quantity and quality could be a potential way to support employees' work ability and possibly even to postpone retirement, at least in relation to early retirement. Possible proposed mechanisms for the improved sleep after retirement include removal of work stress and increased flexibility in time use, which could be targeted in attempt to promote adequate and good quality of sleep already during the working years.
\end{abstract}

Keywords Retirement · Statutory retirement · Disability retirement $\cdot$ Sleep duration $\cdot$ Sleep quality $\cdot$ Insomnia $\cdot$ Aging

\section{Introduction}

The present review focuses on the associations between sleep and retirement, a particularly timely topic, as the large babyboomer generation is currently moving into retirement. Sleep not only is a key characteristic of health and well-being but also highly relevant in relation to work ability, as poor sleep is associated with lower work productivity, work absenteeism, and accidents [1, 2] as well as sickness absence [3-5]. Thus, adequate amount and quality of sleep are potential factors to be considered when aiming to prolong labor force participation and to postpone retirement. In regard to the association between sleep and retirement, the other interesting viewpoint is how sleep changes when people retire from work. Retirement provides an optimal window for positive changes in sleep as working hours no longer dominate sleep timings and work-related stressors are removed.

This article is part of the Topical Collection on Sleep and Aging

Saana Myllyntausta

saana.myllyntausta@utu.fi

1 Department of Public Health, University of Turku and Turku University Hospital, Turku, Finland
In this review, we present and summarize the current literature on the associations of sleep and retirement while considering both approaches: the role of sleep on retirement timing and the impact of retirement on sleep. We begin by exploring how the quality and duration of sleep during the working years associate with retirement timing, especially early retirement and disability retirement. Next, we will review the literature on the changes observed in both sleep difficulties and sleep duration following the transition from work to retirement. Finally, we conclude by discussing the wider societal implications of these findings.

\section{Sleep and Retirement Timing}

Most of the literature on the association of sleep and the timing of retirement focuses on disability retirement (Table 1), a permanent deterioration of work ability due to illness, injury, or impairment, which prevents from continuing working. Those with frequent sleep problems have been found to have the highest risk for not returning to work from any disability period [6] and for subsequent disability retirement [7-11], but even occasional sleep problems have been found to predict disability retirement [10]. However, in terms of the association between sleep duration and disability retirement, the findings 


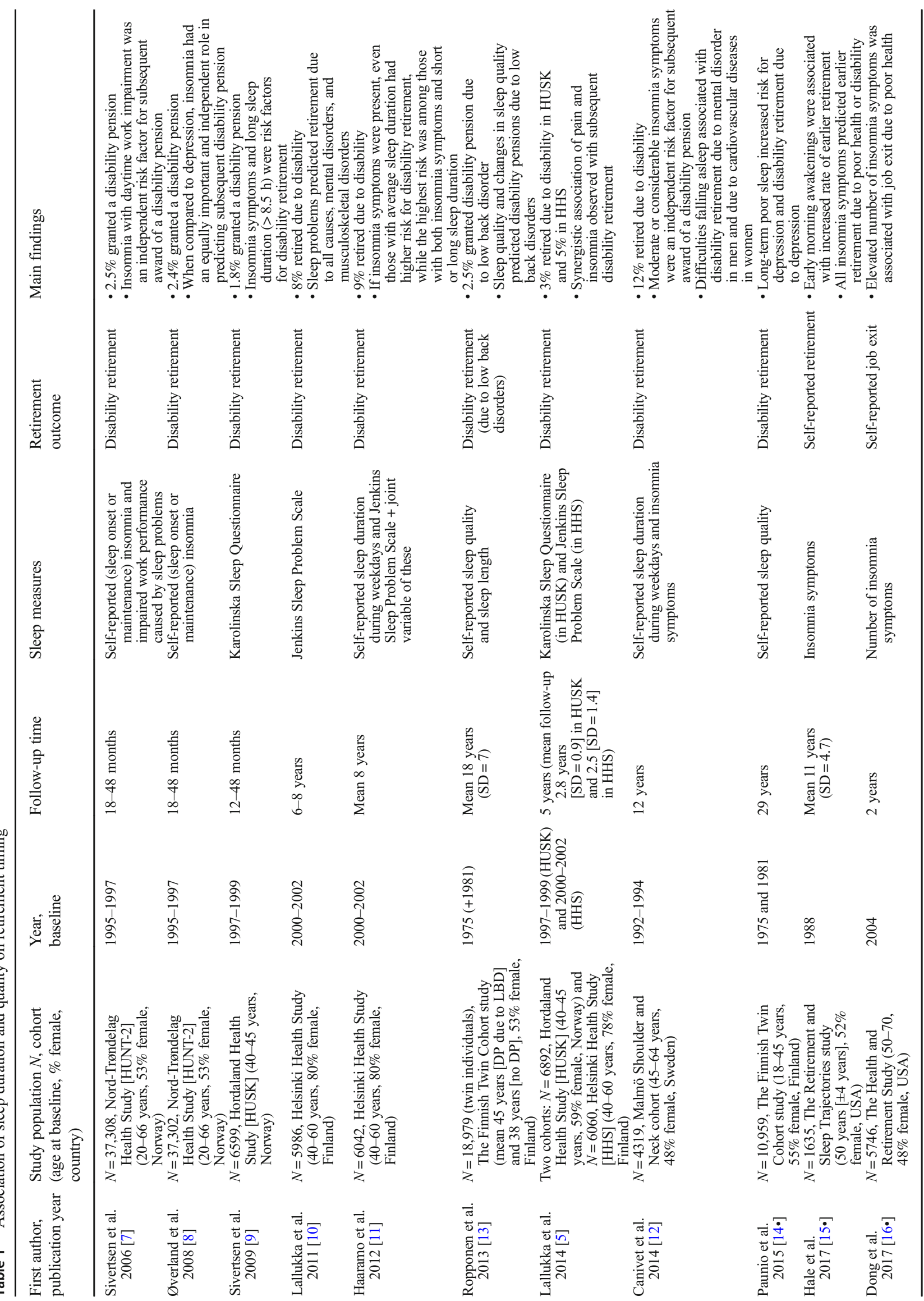


are somewhat contradictory. Some studies report that those workers with either short $(\leq 5 \mathrm{~h})$ or long $(\geq 9 \mathrm{~h})$ sleep are more likely to retire due to disability than those with average sleep (7-8 h) [11], while some studies have found this association only among long sleepers $[9,12]$ and some not at all [13]. The simultaneous examination of sleep duration and insomnia symptoms has revealed that even those with average sleep duration had a higher risk for subsequent disability retirement if they simultaneously experienced insomnia symptoms and, on the other hand, there was a much lower risk for disability retirement among short and long sleepers if frequent insomnia symptoms were not present [11]. Thus, the quality of sleep seems to play a stronger role than sleep duration in predicting the risk of work disability and disability retirement.

Some research has also focused on cause-specific disability retirement including retirement due to musculoskeletal disorders $[10,11,13]$ and mental disorders $[10-12,14 \bullet]$. Selfreported short sleep duration $(\leq 5 \mathrm{~h})$ and frequent insomnia symptoms have been found to predict disability retirement due to both musculoskeletal disorders and mental disorders $[10,11]$. In addition, men with sleep disturbances have been observed to have a higher risk for not returning to work following a disability caused by a mental disorder or disease of musculoskeletal system than men without sleep disturbances [6]. Fairly poor or poor quality of sleep has also been found to predict subsequent disability retirement due to low back disorder [13]. In addition, those reporting insomnia symptoms and pain simultaneously were observed to have the highest risk for disability retirement, suggesting a synergistic effect of insomnia symptoms and pain [5]. Furthermore, an onset of poor sleep has been found to predict incident depression and to increase risk of disability retirement due to depression almost threefold [14•]. Based on these findings, it can be postulated that an early detection and treatment of insomnia and other sleep problems is important and could potentially help to maintain workers' work ability and to prevent disability retirement. This would seem to be particularly important among workers retiring due to low back disorder and depression.

All of the abovementioned studies on disability retirement have obtained the retirement data from pension registers, which is regarded as highly accurate and objective data source, and usually includes information on both the exact timing and the diagnosis the disability pension is based on. There are, however, also few studies that have used selfreported job exit/retirement as an outcome instead and focused on different reasons for retirement $[15 \bullet, 16 \bullet$. The findings from these two studies are consistent with those examining disability retirement as the outcome showing an association with insomnia symptoms and subsequent job exit due to poor health, but not due to other reasons. Thus, these studies strengthen the findings of poor sleep quality being related to retirement due to poor health in particular.
Despite relatively consistent findings, there are also challenges in examining the role of sleep on disability retirement. As disability retirement is always preceded by a diagnosis of a disease or chronic condition, it may be difficult to isolate the impact of sleep from other factors and health in general. It can be presumed that poor sleep may lead to deteriorated health and work ability, but other factors, such as work-related factors and health behaviors, might also mediate the association between sleep and subsequent disability retirement, or on the contrary, be the cause of the poor sleep [12]. Many of the previous studies have controlled for possible confounders, such as work stress and obesity, physical activity, and other health behavioral factors, and found the associations between poor sleep and disability retirement to attenuate, but nevertheless remain significant after these adjustments.

In addition to current literature on the associations of poor sleep quality and inadequate duration with subsequent negative outcomes in employment, such as sickness absences and early retirement, it would be worth examining whether good sleep has positive effects on employment and extending working careers beyond the statutory retirement ages. To the best of our knowledge, there is currently no knowledge on whether those who sleep well during the working years are more likely to continue working longer and, thus, to postpone their retirement. Such finding would further emphasize the importance of promoting the sleep of employees when aiming to support work ability of older employees and to prolong their labor force participation.

\section{Changes of Sleep During the Transition to Retirement}

With increasing number of people retiring, the changes in sleep following retirement have gained more interest during the previous years and both the changes in sleep duration and sleep quality have been examined. The first studies examined retirement and sleep by comparing those already retired to those still working in cross-sectional settings $[17,18,19 \bullet \cdot]$. The main limitation with these studies is that the differences observed in sleep between workers and retirees may not be due to retirement per se, but due to differences between the individuals who retire and those who continue working. In recent years, a few longitudinal studies have emerged in which sleep of the participants has been repeatedly measured before and after retirement allowing examination of true changes during retirement transition $[20,21,22 \bullet, 23 \bullet, 24 \bullet]$.

Retirement is a major life transition for the individual as daily schedules and activities are altered with working hours removed from the schedule. These changes may potentially lead to decreases in daytime structure as well as to less regular sleeping patterns. For example, it is possible to stay in bed longer in the mornings as well as to take daytime naps more 
freely after retirement. These potential changes in sleeping patterns could in turn lead to reduced homeostatic sleep pressure [25] and, consequently, to a poorer quality of sleep during the nights.

However, findings from recent studies suggest that retirement may have a beneficial effect on sleep quality. Longitudinal studies from French and Finland have observed, for instance, that sleep difficulties decrease substantially following retirement $[20,24 \bullet]$. When changes in different types of sleep difficulties have been examined, decreases have been observed especially in premature awakenings [21, 24•] and nonrestorative sleep, that is feeling tired and worn out after the usual amount of sleep [24•]. These improvements in sleep quality have been suggested to be driven by the removal of work stress, as the observed decreases in sleep disturbances have been most prevalent among those with job strain and psychological distress before retirement [20, 24•]. Psychosocial stress is associated with poor sleep quality [26, 27•], and after retirement, the work-related stressors are removed. The improvements in sleep quality might also be due to positive changes in lifestyle and health which have been observed following retirement $[28,29]$ or due to the demands on health being lower after the obligation to be able to work is removed. It is also possible that the changes in sleep quality are in fact changes in how sleep is perceived and reported; for example, difficulties falling asleep and waking up during the night might not be experienced as disturbing as during the working years, as poor sleep can be compensated for by sleeping longer in the morning or by taking naps during the following day. In addition, the pressure to acquire an adequate amount of good quality sleep to be able to work on the following day is removed.

Also, changes in sleep duration during retirement transition have been examined in two recent longitudinal studies [22 23•]. The results show that sleep duration increases following a transition to retirement among both men and women. Highly similar levels of increases in sleep duration were observed in these studies, with the first one [22•] reporting 15, 16, and 22 min longer sleep durations 1,2 , and 3 years postretirement among retirees than among those who continued working full time over the same period and the other one [23•] observing an increase of $22 \mathrm{~min}$ during a four-year period around the transition to retirement. The most pronounced increases in sleep duration following retirement have been observed to occur among those with short sleep duration ( $\leq$ $6.5 \mathrm{~h} / 24 \mathrm{~h}$ ), sleep difficulties, heavy alcohol use, and psychological distress before retirement [23•]. In addition, a study examining changes in time use following retirement observed an increase in the time used for sleeping of approximately 30 min already 3 months post-retirement [30]. One explanation for increased sleep duration may be that leisure time increases after retirement as working hours are removed, and this may allow more time being devoted to sleeping. In addition, retirement removes the pressure to sleep at fixed times, working hours no longer dominate sleeping patterns, and there is no need to use an alarm clock; thus, there is a possibility to sleep longer during the mornings. Along with increased sleep duration, later bed times and wake times have been observed [22•].

These findings of improved duration and quality of sleep after retirement are important, as by understanding how retirement affects sleep and who benefit most of retirement, it may be possible to promote positive changes in sleep before and after retirement as well. Improvements in sleep may also translate into better daily functioning $[31,32 \cdot]$ and quality of life $[33,34]$. In fact, retirement has been associated with both decreases in mental and physical fatigue [35] and improved self-rated health [27]. A major limitation of the previous literature is its reliance on self-reported information on sleep. The only exception to the previous literature is provided by a unique case study [36 $6^{\circ}$ in which the author wore an accelerometer continuously for more than three decades and observed that the difference in sleep duration between weekday and weekends/days off diminished after retirement. Repeatedly conducted accelerometer measurements would indeed provide more accurate and reliable assessment of changes in sleep duration and quality around the retirement transition. With accelerometers, it would also be possible to examine the interrelationship between sleep duration and quality. Moreover, conducting measurements on both weekday and weekend nights would allow detailed examination of changes in the timing and variability of sleep. As there are already some implications on changes to later bed times and wake times after retirement [22•], it would also be valuable to examine whether different changes are observed among people with different circadian preferences (i.e., the morning and the evening types). For example, it could be examined whether those with evening preference benefit more from retirement in relation to sleep, as after retirement, they may adjust their sleeping patterns according to their preferences which may not have been possible during the working years due to externally imposed temporal patterns.

\section{Conclusions}

As the baby boomer generation is moving into retirement, and the old-age dependency ratio is increasing, many Western governments are aiming at prolonging the labor force participation and raising the retirement ages. Based on the reviewed literature, promoting adequate sleep quantity and quality of employees could be a potential way to support their work ability and possibly even to postpone retirement, at least in the case of early retirement and disability retirement. However, as it is not yet known whether good quality sleep has protective effects on employment, such as being able to 
continue in the work force beyond the statutory retirement age, further research is needed on this topic. Moreover, transitioning to retirement seems to have positive effects on sleep, and improvements have been observed in both sleep duration and quality. The removal of work stress and the increased flexibility in time use have been proposed as potential mechanisms for the improvements in sleep after retirement. Thus, better sleep among older workers could possibly be promoted by, e.g., reducing work stress and with better work-time control. To date, the research on the associations of retirement and sleep, in relation to both the timing of retirement and the changes in sleep following it, has been almost entirely conducted in Northern Europe (Finland, Sweden, and Norway) and the USA using self-reported methods. Thus, further research is needed to examine whether similar findings are observed in other cultures, countries, and working sectors with different retirement schemes and by using objective measurements of sleep.

Funding Information This study was financially supported by Yrjo Jahnsson Foundation (to SM), Juho Vainio Foundation (to SM), University of Turku Graduate School/Doctoral Programme in Clinical Research (to SM), the Academy of Finland (grant numbers 286294 and 294154 to SS) and Finnish Work Environment Fund (grant number 118060).

\section{Compliance with Ethical Standards}

Conflict of Interest Saana Myllyntausta reports grants from Juho Vainio Foundation, Finnish Work Environment Fund, and Yrjo Jahnsson Foundation.

Sari Stenholm reports grants from Academy of Finland and Finnish Work Environment Fund.

Human and Animal Rights and Informed Consent This article does not contain any studies with human or animal subjects performed by any of the authors.

Open Access This article is distributed under the terms of the Creative Commons Attribution 4.0 International License (http:// creativecommons.org/licenses/by/4.0/), which permits unrestricted use, distribution, and reproduction in any medium, provided you give appropriate credit to the original author(s) and the source, provide a link to the Creative Commons license, and indicate if changes were made.

\section{References}

Papers of particular interest, published recently, have been highlighted as:

- Of importance

•. Of major importance

1. Daley M, Morin CM, LeBlanc M, Gregoire JP, Savard J, Baillargeon L. Insomnia and its relationship to health-care utilization, work absenteeism, productivity and accidents. Sleep Med. 2009;10:427-38. https://doi.org/10.1016/j.sleep.2008.04. 005 .

2. Kucharczyk ER, Morgan K, Hall AP. The occupational impact of sleep quality and insomnia symptoms. Sleep Med Rev. 2012;16: 547-59. https://doi.org/10.1016/j.smrv.2012.01.005.

3. Sivertsen B, Øverland S, Bjorvatn B, Mæland JG, Mykletun A. Does insomnia predict sick leave?: the Hordaland health study. J Psychosom Res. 2009;66:67-74. https://doi.org/10.1016/j. jpsychores.2008.06.011.

4. Rahkonen O, Lallukka T, Kronholm E, Vahtera J, Lahelma E, Laaksonen M. Sleep problems and sickness absence among middle-aged employees. Scand J Work Environ Health. 2012;38: 47-55. https://doi.org/10.5271/sjweh.3186.

5. Lallukka T, Øverland S, Haaramo P, Saastamoinen P, Bjorvatn B, Sivertsen $B$. The joint contribution of pain and insomnia to sickness absence and disability retirement: a register-linkage study among Norwegian and Finnish employees. Eur J Pain. 2014;18:883-92. https://doi.org/10.1002/j.1532-2149.2013.00432.x.

6. Salo P, Oksanen T, Sivertsen B, Hall M, Pentti J, Virtanen M, et al. Sleep disturbances as a predictor of cause-specific work disability and delayed return to work. Sleep. 2010;33:1323-31. https://doi. org/10.1093/sleep/33.10.1323.

7. Sivertsen B, Øverland S, Neckelmann D, et al. The long-term effect of insomnia on work disability: the HUNT-2 historical cohort study. Am J Epidemiol. 2006;163:1018-24. https://doi.org/10.1093/aje/ kwj145.

8. Øverland S, Glozier N, Sivertsen B, et al. A comparison of insomnia and depression as predictors of disability pension: the HUNT study. Sleep. 2008;31:875-80. https://doi.org/10.1093/sleep/31.6. 875.

9. Sivertsen B, Øverland S, Pallesen S, et al. Insomnia and long sleep duration are risk factors for later work disability. The Hordaland health study. J Sleep Res. 2009;18:122-8. https://doi.org/10.1111/j. 1365-2869.2008.00697.x.

10. Lallukka T, Haaramo P, Lahelma E, Rahkonen O. Sleep problems and disability retirement: a register-based follow-up study. Am J Epidemiol. 2011;173:871-81. https://doi.org/10.1093/aje/kwq462.

11. Haaramo P, Rahkonen O, Lahelma E, Lallukka T. The joint association of sleep duration and insomnia symptoms with disability retirement - a longitudinal, register-linked study. Scand J Work Environ Health. 2012;38:427-35. https://doi.org/10.5271/sjweh. 3269.

12. Canivet C, Staland-Nyman C, Lindeberg SI, Karasek R, Moghaddassi M, Östergren P. Insomnia symptoms, sleep duration, and disability pensions: a prospective study of Swedish workers. Int J Behav Med. 2014;21:319-28. https://doi.org/10.1007/ s12529-013-9315-0.

13. Ropponen A, Silventoinen K, Hublin C, Svedberg P, Koskenvuo M, Kaprio J. Sleep patterns as predictors for disability pension due to low back diagnoses: a 23-year longitudinal study of Finnish twins. Sleep. 2013;36:891-7. https://doi.org/10.5665/sleep.2718.

14. Paunio T, Korhonen T, Hublin C, et al. Poor sleep predicts symptoms of depression and disability retirement due to depression. $\mathrm{J}$ Affect Disord. 2015;172:381-9. https://doi.org/10.1016/j.jad.2014. 10.002. This study provides evidence that poor sleep predicts incident depression and disability retirement due to depression.

15. Hale L, Singer L, Barnet JH, Peppard PE, Hagen EW. Associations between midlife insomnia symptoms and earlier retirement. Sleep Health. 2017;3:170-7. https://doi.org/10.1016/j.sleh.2017.03.003. This study provides evidence that insomnia symptoms predicts earlier self-reported retirement due to poor health or disability.

16. Dong L, Agnew J, Mojtabai R, Surkan PJ, Spira AP. Insomnia as a predictor of job exit among middle-aged and older adults: results from the health and retirement study. J Epidemiol Community 
Health. 2017:208630. https://doi.org/10.1136/jech-2016-208630. This study provides evidence that insomnia symptoms in midlife associate with job exit due to poor health.

17. Kronholm E, Hyyppä MT. Age-related sleep habits and retirement. Ann Clin Res. 1985;17:257-64.

18. Ito Y, Tamakoshi A, Yamaki K, Wakai K, Kawamura T, Takagi K, et al. Sleep disturbance and its correlates among elderly Japanese. Arch Gerontol Geriatr. 2000;30:85-100. https://doi.org/10.1016/ S0167-4943(99)00054-0.

19.• van de Straat V, Bracke P. How well does Europe sleep? A crossnational study of sleep problems in European older adults. Int $\mathrm{J}$ Public Health. 2015;60:643-50. https://doi.org/10.1007/s00038015-0682-y. This study explores the cross-country variations in impaired sleep in a representative sample of the European older population from 16 countries.

20. Vahtera J, Westerlund H, Hall M, Sjösten N, Kivimäki M, Salo P, et al. Effect of retirement on sleep disturbances: the GAZEL prospective cohort study. Sleep. 2009;32:1459-66. https://doi.org/10. 1093/sleep/32.11.1459.

21. Marquié J, Folkard S, Ansiau D, Tucker P. Effects of age, gender, and retirement on perceived sleep problems: results from the VISAT combined longitudinal and cross-sectional study. Sleep. 2012;35:1115-21. https://doi.org/10.5665/sleep.2000.

22. Hagen EW, Barnet JH, Hale L, Peppard PE. Changes in sleep duration and sleep timing associated with retirement transitions. Sleep. 2016;39:665-73. https://doi.org/10.5665/sleep.5548. This study provides evidence that retirement is associated with longer self-reported sleep duration, later bedtimes, and later wake times.

23. Myllyntausta S, Salo P, Kronholm E, et al. Changes in sleep duration during transition to statutory retirement: a longitudinal cohort study. Sleep. 2017;40:zsx087. https://doi.org/10.1093/sleep/ zsx087. This study provides evidence that retirement is associated with increase in sleep duration.

24. Myllyntausta S, Salo P, Kronholm E, et al. Changes in sleep difficulties during the transition to statutory retirement. Sleep. 2018;41: zsx182. https://doi.org/10.1093/sleep/zsx182. This study provides evidence that retirement is associated with decrease in premature awakenings and nonrestorative sleep.

25. Werth E, Dijk D, Achermann P, Borbely A. Dynamics of the sleep EEG after an early evening nap: experimental data and simulations. American journal of physiology-regulatory. Integrative and Comparative Physiology. 1996;1996(271):R501-10. https://doi. org/10.1152/ajpregu.1996.271.3.R501.

26. Van Laethem M, Beckers DGJ, Kompier MAJ, Dijksterhuis A, Geurts SAE. Psychosocial work characteristics and sleep quality: a systematic review of longitudinal and intervention research.
Scand J Work Environ Health. 2013;39:535-49. https://doi.org/ 10.5271/sjweh.3376.

27. Åkerstedt T, Garefelt J, Richter A, et al. Work and sleep-a prospective study of psychosocial work factors, physical work factors, and work scheduling. Sleep. 2015;38:1129-36. https://doi.org/10. 5665/sleep.4828. This study provides evidence that higher work demands predicts sleep disturbances.

28. Westerlund H, Kivimäki M, Singh-Manoux A, Melchior M, Ferrie JE, Pentti J, et al. Self-rated health before and after retirement in France (GAZEL): a cohort study. Lancet. 2009;374:1889-96. https://doi.org/10.1016/S0140-6736(09)61570-1.

29. Stenholm S, Pulakka A, Kawachi I, Oksanen T, Halonen JI, Aalto $\mathrm{V}$, et al. Changes in physical activity during transition to retirement: a cohort study. Int J Behav Nutr Phys Act. 2016;13:51. https://doi. org/10.1186/s12966-016-0375-9.

30. Sprod J, Olds T, Brown W, Burton N, van Uffelen J, Ferrar K, et al. Changes in use of time across retirement: a longitudinal study. Maturitas. 2017;100:70-6. https://doi.org/10.1016/j.maturitas. 2017.02.018.

31. Stenholm S, Kronholm E, Bandinelli S, Guralnik JM, Ferrucci L. Self-reported sleep duration and time in bed as predictors of physical function decline: results from the InCHIANTI study. Sleep. 2011;34:1583-93. https://doi.org/10.5665/sleep.1402.

32. Lallukka T, Sivertsen B, Kronholm E, Bin YS, Øverland S, Glozier N. Association of sleep duration and sleep quality with the physical, social, and emotional functioning among Australian adults. Sleep Health. 2018;4:194-200. https://doi.org/10.1016/j.sleh.2017.11. 006. This study provides evidence that poor sleep is associated with worse physical, emotional, and social functioning.

33. LeBlanc M, Beaulieu-Bonneau S, Mérette C, Savard J, Ivers H, Morin CM. Psychological and health-related quality of life factors associated with insomnia in a population-based sample. J Psychosom Res. 2007;63:157-66. https://doi.org/10.1016/j. jpsychores.2007.03.004.

34. Kyle SD, Morgan K, Espie CA. Insomnia and health-related quality of life. Sleep Med Rev. 2010;14:69-82. https://doi.org/10.1016/j. smrv.2009.07.004.

35. Westerlund H, Vahtera J, Ferrie JE, Singh-Manoux A, Pentti J, Melchior M, et al. Effect of retirement on major chronic conditions and fatigue: French GAZEL occupational cohort study. The BMJ. 2010;341:c6149. https://doi.org/10.1136/bmj.c6149.

36. Borbély AA, Rusterholz T, Achermann P. Three decades of continuous wrist-activity recording: analysis of sleep duration. J Sleep Res. 2017;26:188-94. https://doi.org/10.1111/jsr.12492. This unique case study explores the changes in objective sleep over three decades. 